Open Access : ISSN : 1848-7718

Erratum

http://www.pub.iapchem.org/ojs/index.php/admet/index

\title{
Erratum to the paper: In vitro membrane binding and protein binding (IAM MB/PB technology) to estimate in vivo distribution: applications in early drug discovery
}

\author{
Klara Valko* ${ }^{1}$, Simon Teague ${ }^{2}$, Charles Pudgeon ${ }^{3}$ \\ ${ }^{1}$ Bio-Mimetic Chromatography Ltd, Unit 5B Business \& Technology Centre, Stevenage, SG1 2DX Hertfordshire United \\ Kingdom \\ ${ }^{2}$ GlaxoSmithKline, Stevenage, United Kingdom \\ ${ }^{3}$ Independent Researcher, affiliate of Regis Technologies Inc, Morton Grove, IL 60052 USA
}

*Corresponding Author: E-mail: Klara Valko@bio-mimetic-chromatofraphy.com; Tel.: +44-7521-989558

Received: July 11, 2018; Revised: July 12, 2018; Available online: July 15, 2018

The authors of the original paper published with the same title [1] apologize for the error in the plot on Figure 5.

The correct plot, statistics and explanation in Figure 5 on page 25 using the published data in the Appendix Table $\mathrm{A} 1$ and $\mathrm{A} 2$ by equation 3 are shown below.

"In turn, the volume of distribution of marketed drugs could be modeled by the difference in the membrane and the protein binding of compounds as described by Equation 3 and shown in Figure 5 for the investigated compounds. There are only 40 compounds that have been included in the training set, the majority of the compounds were not included in the original model. That explains that the statistics are slightly worse $\left(r^{2}=0.76\right.$; root mean square error $=0.33$ in the original model, while here the $r^{2}=0.65$ and root mean square error $=0.40)$. “

It is considered as an excellent prediction of the in vivo behaviour of the compounds using only two measured biomimetic properties, namely the IAM membrane binding and the HSA protein binding (see the original paper for details). 


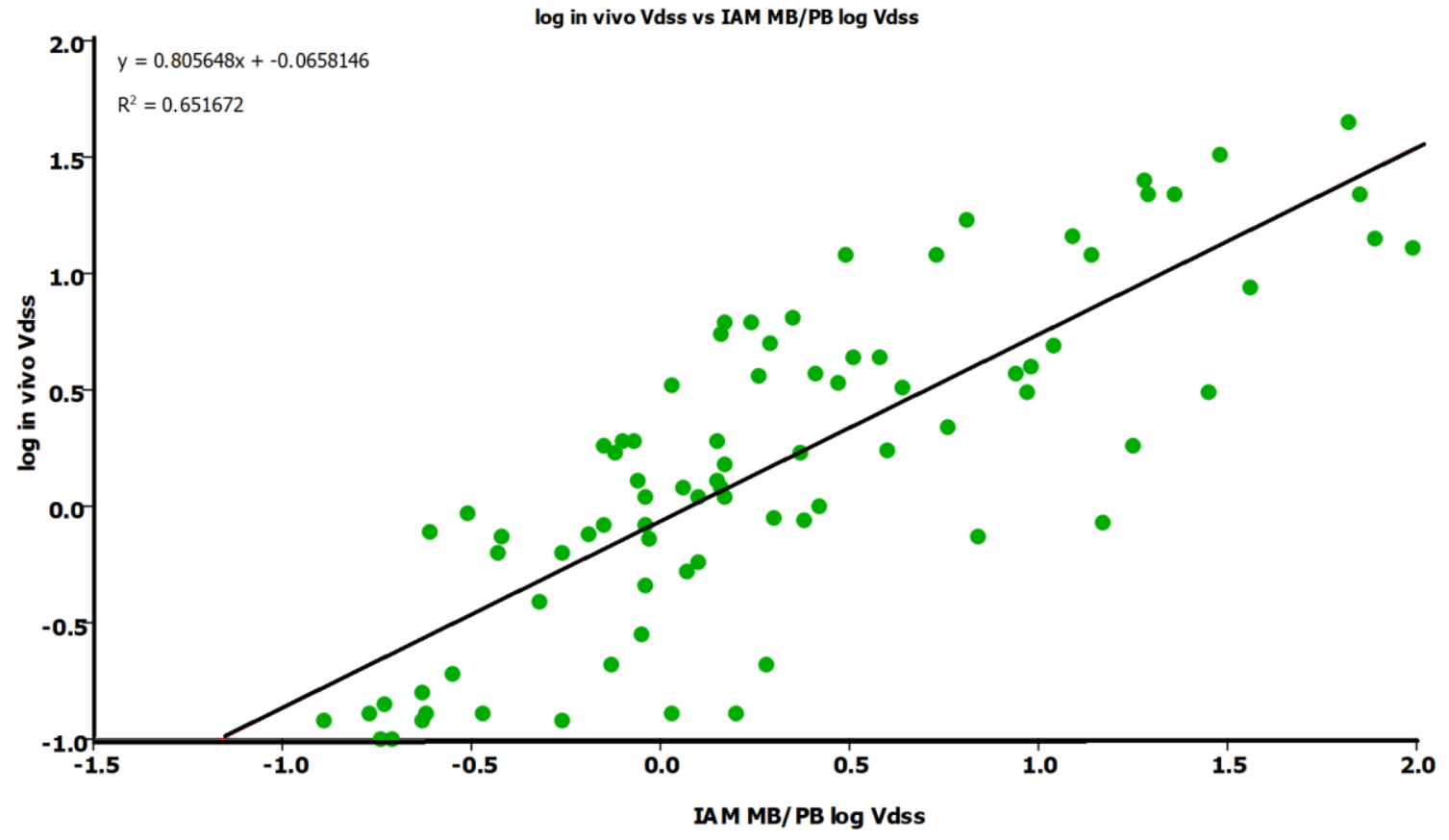

Figure 5. The observed in vivo log Vdss vs the estimated Vdss by the IAM MB/PB Technology ${ }^{\circledR}$ using Equation 3.

\section{References}

[1] K. Valko, S. Teague, C. Pudgeon. In vitro membrane binding and protein binding (IAM MB/PB technology) to estimate in vivo distribution: applications in early drug discovery. ADMET \& DMPK 5(1) (2017) 14-38. https://dx.doi.org/10.5599/admet.5.1.373

(C)2018 by the authors; licensee IAPC, Zagreb, Croatia. This article is an open-access article distributed under the terms and conditions of the Creative Commons Attribution license (http://creativecommons.org/licenses/by/3.0/) (cc) $\mathrm{EY}$ 